International Journal of Advanced Geosciences, 8(2) (2020) 193-196
International Journal of Advanced Geosciences
SPC
Website: www.sciencepubco.com/index.php/IJAG
Research paper

\title{
Precipitation concentration index (PCI) a tool to evaluate the distribution of Rainfall, Barishal, Bangladesh
}

\author{
Sudip Saha * \\ Department of Geology and Mining, University of Rajshahi, Rajshahi-6205, Bangladesh \\ *Corresponding author E-mail: sudips_geologist@yahoo.com
}

\begin{abstract}
The present research work reveals the mean annual rainfall of Barishal is $2087.34 \mathrm{~mm}$ for the investigated period. The maximum annual rainfall was $3390 \mathrm{~mm}$ in the year of 1960 and minimum annual rainfall was recorded as $1277 \mathrm{~mm}$ in the year of 1964 . The annual rainfall is inversely correlated with time. The maximum monthly rainfall is recorded in the month of July. The amount of annual rainfall is strongly significantly positively correlated with the monthly rainfall of May, June, July, August and September. In Barishal, the value of skewness for all rainfall data are positive that indicate the data are skewed to the right. The positive value of kurtosis of the eleven months of the year (except July) means a peaked distribution and a negative value in the month of July reveals the flat distribution with the same mean and standard deviation. The annual PCI value is inversely proportional to the annual rainfall. The analyses of seasonal precipitation concentration index (SPCI) reveals that the rainfall is uniformly distributed in summer monsoon whereas the winter rainfall shows the dominance of strong irregularity in precipitation distribution.
\end{abstract}

Keywords: Precipitation Concentration Index (PCI); Annual Rainfall; Inversely; Summer Monsoon and Barishal.

\section{Introduction}

Precipitation directly influence the water availability of an area and it is one of the most important climatic and hydrological parameters (De Luis et al. 2011). In tropical areas rainfall is the main form of precipitation. The precipitation concentration index (PCI) is used to measure the temporal precipitation distribution and seasonal precipitation distribution (Zhang et al. 2019).

The study area lies in Barishal district, which is in the southern part of Bangladesh. Figure 1 shows that the study area is surrounded by numerous rivers. The rivers are tidal is nature (Saha et al.2020; Moniruzzaman et al. 2016). The main rivers of Barishal are the Meghna, Kirtonkhola, Jayanti etc. The surface geology is principally composed of sand, silt and clay of either estuarine or deltaic origin of Quaternary age. The clay particles mainly composed of illite, kaolinite, chlorite, quartz and feldspars (Saha et al. 2020).

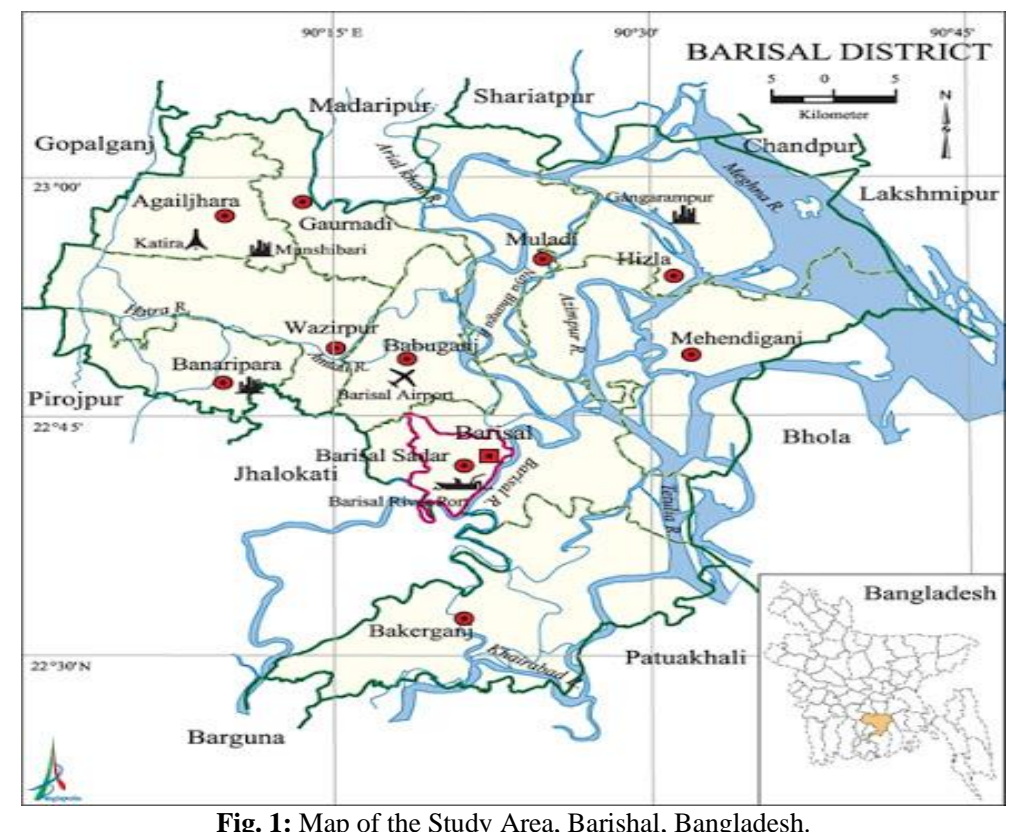

Fig. 1: Map of the Study Area, Barishal, Bangladesh. 


\section{Methodology}

Daily rainfall data of Barishal, Bangladesh was downloaded from website of BMD. From the daily rainfall data, total monthly rainfall was calculated using necessary computer software. The total annual rainfall was calculated by adding the total monthly rainfalls of twelve months of that year. The mean monthly rainfall and mean annual rainfall were analyzed. The required graphs were drawn. The Pearson correlation coefficients were calculated. The other statistical parameters such as mean, median standard deviation, skewness and kurtosis were calculated to analyze the yearly and monthly data (Islam et al. 2019). The precipitation concentration index was calculated as described Zhang et al. 2019.

\section{Results and discussion}

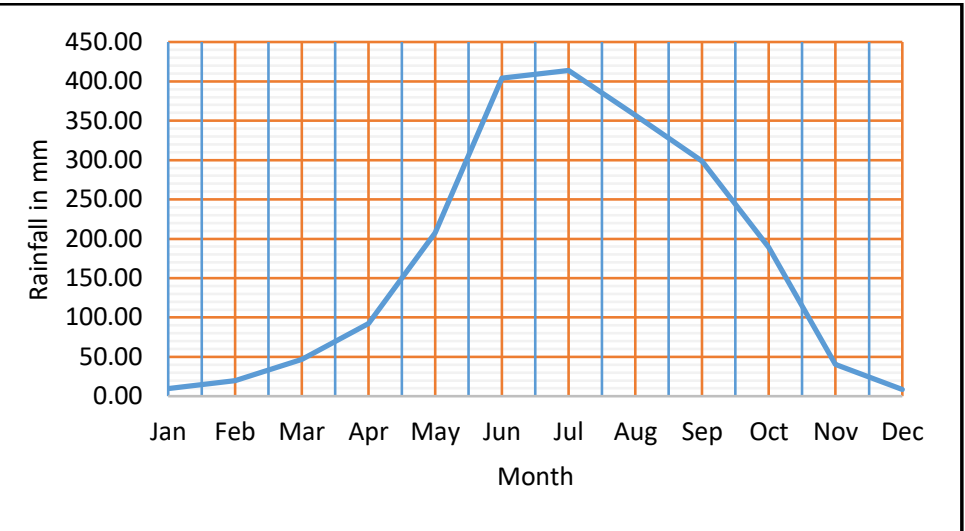

Fig. 2: Annual Mean Rainfall Distribution of Barishal.

Figure 2 shows the annual mean rainfall distribution of Barishal and the maximum rainfall occurs in the month of July, whereas minimum monthly rainfall was recorded in the month of December. Figure 3 reveals the distribution of annual total rainfall of Barishal station during 1950-2013. The analysis of rainfall data shows that the average annual rainfall of Barishal for the investigated period is $2087.34 \mathrm{~mm}$. The maximum annual rainfall was $3390 \mathrm{~mm}$ in the year of 1960 and minimum annual rainfall was recorded as $1277 \mathrm{~mm}$ in the year of 1964 . The annual rainfall is inversely correlated with time (Figure 3).

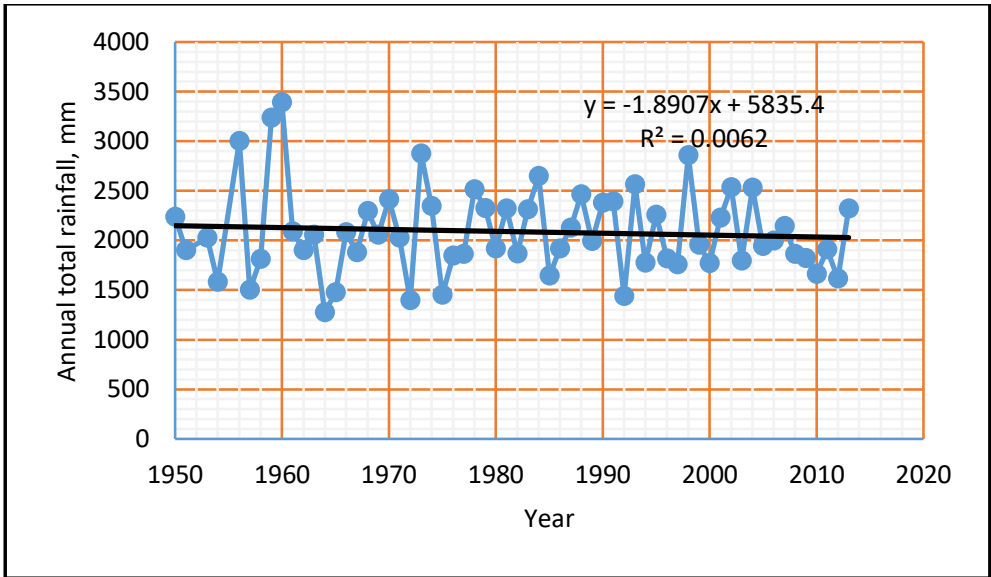

Fig. 3: Annual Rainfall Distribution, Barishal, Bangladesh.

Table 1: Statistical Summary of Monthly Rainfall Data of Barishal

\begin{tabular}{|c|c|c|c|c|c|c|c|c|c|c|c|c|}
\hline $\begin{array}{l}\text { Parame- } \\
\text { ter }\end{array}$ & Jan & Feb & Mar & Apr & May & Jun & Jul & Aug & Sep & Oct & Nov & Dec \\
\hline $\begin{array}{l}\text { Mean } \\
(\mathrm{mm})\end{array}$ & 9.55 & 19.97 & 46.53 & 92.06 & 207.55 & 404.23 & 413.85 & 356.79 & 298.82 & 189.11 & 40.35 & 8.52 \\
\hline $\begin{array}{l}\text { Median } \\
(\mathrm{mm})\end{array}$ & 0.00 & 12.50 & 19.00 & 88.00 & 186.00 & 381.50 & 395.50 & 334.00 & 249.50 & 170.00 & 15.50 & 0.00 \\
\hline $\begin{array}{l}\text { SD } \\
(\mathrm{mm})\end{array}$ & 23.93 & 25.02 & 63.84 & 80.79 & 122.99 & 178.89 & 136.79 & 144.09 & 169.32 & 118.36 & 58.23 & 27.05 \\
\hline $\begin{array}{l}\text { Vari- } \\
\text { ance }\end{array}$ & 572.55 & 626.00 & 4075.96 & 6526.29 & 15126.51 & 32002.28 & 18712.19 & 20762.37 & 28667.72 & 14009.84 & 3390.82 & 731.93 \\
\hline $\begin{array}{l}\text { Skew- } \\
\text { ness }\end{array}$ & 4.39 & 1.40 & 2.03 & 1.54 & 1.26 & 1.02 & 0.51 & 0.90 & 2.01 & 0.70 & 2.27 & 5.87 \\
\hline Kurtosis & 21.66 & 1.27 & 4.10 & 3.38 & 3.07 & 1.43 & -0.35 & 0.71 & 6.28 & -0.04 & 5.99 & 39.71 \\
\hline $\begin{array}{l}\text { Max } \\
(\mathrm{mm})\end{array}$ & 148.00 & 98.00 & 273.00 & 412.00 & 701.00 & 1025.00 & 751.00 & 823.00 & 1067.00 & 497.00 & 270.00 & 197.00 \\
\hline $\begin{array}{l}\text { Min } \\
(\mathrm{mm})\end{array}$ & 0.00 & 0.00 & 0.00 & 0.00 & 22.00 & 139.00 & 185.00 & 138.00 & 0.00 & 6.00 & 0.00 & 0.00 \\
\hline $\begin{array}{l}\text { Range } \\
(\mathrm{mm})\end{array}$ & 148.00 & 98.00 & 273.00 & 412.00 & 679.00 & 886.00 & 566.00 & 685.00 & 1067.00 & 491.00 & 270.00 & 197.00 \\
\hline $\begin{array}{l}\text { Sum } \\
(\mathrm{mm})\end{array}$ & 592.00 & 1238.00 & 2885.00 & 5708.00 & 12868.00 & 25062.00 & 25659.00 & 22121.00 & 18527.00 & 11725.00 & 2502.00 & 528.00 \\
\hline
\end{tabular}


The mean monthly rainfall value for the month of January is $9.55 \mathrm{~mm}$. The monthly rainfall value is zero in January for 33 years. The median value for monthly rainfall is $12.55 \mathrm{~mm}$ for the month of February (Table 1). The average monthly rainfall is $46.53 \mathrm{~mm}$ for the month of March. The monthly rainfall values show inverse correlation with time (year) for the months of January, June, July, August, September, October, November, December and positive correlation for the months of February, March, April and May.

\section{Statistical analysis of Rainfall of Barishal}

Table 1 shows the results of statistical analyses of rainfall data in millimeters. The amount of rainfall starts to increase from the month of February, reaches to the peak in July and then starts to reduce in amounts. The highest monthly rainfall was recorded in September 2004 whose numerical value was $1067 \mathrm{~mm} .89 .4 \%$ of the annual rainfall occur in the months of May, June, July, August, September and October. The analyses show that it rained in every year in the month of May, June, July and August as the minimum monthly value for these months were greater than zero within the investigated period. The standard deviation and range decipher the variability of annual rainfall and signify how reliable the rainfall in terms of its persistence as constant and stable replenishing source (Islam 2019). A higher standard deviation value shows that the rainfall is spread wide on the either sides of the mean.

Skewness and kurtosis were computed to test the pattern of annual rainfall data. The skewness for a normal distribution is zero, and any symmetrical data should have skewness value close to zero. Negative skewness values indicate that the data are skewed to the left while the positive skewness values suggest that the data are skewed to the right. In Barishal, the value of skewness for all rainfall data are positive that indicate the data are skewed to the right.

Kurtosis is a measure of peakedness or flatness to normal distribution. The positive value of kurtosis of the eleven months of the year (except July) means a peaked distribution and a negative value in the month of July reveals the flat distribution with the same mean and standard deviation.

\section{Annual precipitation concentration index (PCI)}

Precipitation concentration index (PCI) is an important feature for water resource planning, prediction of risk resulting from droughts or floods and the management of natural resources. Table 2 shows the summary of annual precipitation index of different years of Barishal. On the basis of PCIannual values, it can be concluded that the precipitation distribution was moderate in seven years, irregular in fortyfive years and strongly irregular in ten years. The annual PCI value is inversely proportional to the annual rainfall (Figure 4). The analyses of seasonal precipitation concentration index (SPCI) reveals that the rainfall is uniformly distributed in summer monsoon whereas the winter rainfall shows the dominance of strong irregularity precipitation distribution.

Table 2: Summary of Annual Precipitation Concentration Index ( $\left.\mathrm{Pci}_{\text {annual }}\right)$ and Seasonal Precipitation Concentration Index of Barishal

\begin{tabular}{|c|c|c|c|c|c|c|}
\hline PCI Values & Significance (Temporal distribution) & $\mathrm{PCI}_{\mathrm{ann}}$ & $\mathrm{PCI}_{\mathrm{spr}}$ & $\mathrm{PCI}_{\text {sum }}$ & $\mathrm{PCI}_{\mathrm{atm}}$ & $\mathrm{PCI}_{\mathrm{win}}$ \\
\hline $\mathrm{PCI} \leq 10$ & Uniform precipitation distribution (Low precipitation concentration) & None & 12 & 55 & 7 & 2 \\
\hline PCI $>10 \leq 15$ & Moderate precipitation distribution & 7 & 30 & 7 & 43 & 7 \\
\hline $\mathrm{PCI}>15 \leq 20$ & Irregular precipitation distribution & 45 & 10 & None & 10 & 15 \\
\hline $\mathrm{PCI}>20$ & Strong irregularity precipitation distribution & 10 & 10 & None & 2 & 28 \\
\hline
\end{tabular}

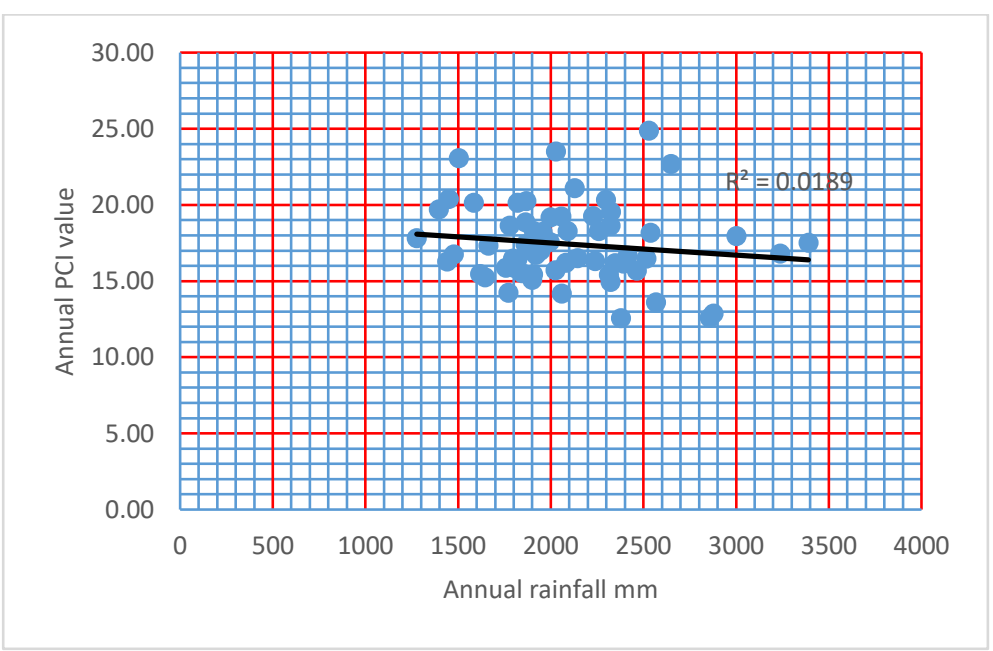

Fig. 4: The Correlation of Annual Rainfall and Annual PCI. 


\section{Discussion}

\begin{tabular}{|c|c|c|c|c|c|c|c|c|c|c|c|c|c|}
\hline & Jan & $\mathrm{Feb}$ & Mar & Apr & May & June & July & Aug & Sep & Oct & Nov & Dec & Annual \\
\hline Jan & 1.000 & & & & & & & & & & & & \\
\hline Feb & 0.049 & 1.000 & & & & & & & & & & & \\
\hline Mar & $0.298^{*}$ & 0.080 & 1.000 & & & & & & & & & & \\
\hline Apr & 0.188 & 0.098 & $0.331^{* *}$ & 1.000 & & & & & & & & & \\
\hline May & -0.160 & -0.079 & 0.125 & 0.102 & 1.000 & & & & & & & & \\
\hline June & -0.181 & -0.075 & -0.107 & -0.029 & $0.252^{*}$ & 1.000 & & & & & & & \\
\hline July & $0.261^{*}$ & 0.034 & 0.132 & -0.005 & 0.117 & -0.071 & 1.000 & & & & & & \\
\hline Aug & 0.048 & -0.006 & 0.001 & -0.074 & 0.037 & 0.006 & 0.212 & 1.000 & & & & & \\
\hline Sep & 0.003 & $-0.303^{*}$ & -0.089 & 0.022 & 0.085 & -0.098 & 0.128 & 0.245 & 1.000 & & & & \\
\hline Oct & -0.102 & -0.159 & 0.098 & $-0.372^{* *}$ & -0.033 & -0.061 & 0.134 & -0.096 & 0.134 & 1.000 & & & \\
\hline Nov & $0.279^{*}$ & $0.283^{*}$ & 0.115 & -0.024 & 0.060 & 0.068 & 0.223 & -0.025 & 0.043 & -0.044 & 1.000 & & \\
\hline Dec & -0.071 & -0.010 & 0.084 & -0.050 & 0.248 & 0.084 & -0.070 & -0.049 & 0.015 & 0.149 & 0.229 & 1.000 & \\
\hline Annual & 0.121 & -0.078 & $0.274^{*}$ & 0.142 & $0.504^{* *}$ & $0.385^{* *}$ & $0.533^{* *}$ & $0.460^{* * *}$ & $0.509^{* *}$ & 0.233 & $0.303^{*}$ & 0.203 & 1.000 \\
\hline
\end{tabular}

The amount of monthly rainfall varies from month to month in a year and in different years of the study area. The amount of rainfall depends mainly on the evaporation of seawater of the Bay of Bengal. The amount of annual rainfall is strongly significantly positively correlated with the monthly rainfall of May, June, July, August and September. The annual total rainfall shows a decreasing trend for Barishal over 1950 to 2013. Similar result (i.e. decreasing trend) also reported for the rainfall data of Barishal division over 1960 to 2015 (Mondal 2016).

The analyses of seasonal precipitation concentration index (SPCI) reveals that the rainfall is uniformly distributed in summer monsoon whereas the winter rainfall shows the dominance of strong irregularity precipitation distribution.

\section{Conclusion}

From the present research work it is revealed that the annual rainfall of Barishal is $2087.34 \mathrm{~mm}$ that showing decreasing trend over the investigated period of time. The magnitude of annual rainfall is strongly significantly positively correlated with the monthly rainfall of May, June, July, August and September. In Barishal, the value of skewness for all rainfall data are positive that indicate the data are skewed to the right. The positive value of kurtosis of the eleven months of the year (except July) means a peaked distribution and a negative value in the month of July reveals the flat distribution with the same mean and standard deviation. The annual PCI value is inversely proportional to the annual rainfall. The analyses of seasonal precipitation concentration index (SPCI) reveals that the rainfall is uniformly distributed in summer monsoon whereas the winter rainfall shows the dominance of strong irregularity precipitation distribution. Further research work can be taken to decipher the seasonal variation of water quality of the study area.

\section{Conflict of interest statement}

Author does not have any conflicts of interest.

\section{Funding}

No funding.

\section{Acknowledgement}

The author is pleased to express his sincere thanks to his teacher Professor Dr. A.H.M., Selim Reza for his kind and continuous advice and inspiration during the research work.

\section{References}

[1] De Luis M, González-Hidalgo JC, Brunetti M and Longares LA (2011) Precipitation concentration changes in Spain 1946-2005. Natural Hazards and Earth System Sciences, 11(5): 1259-1265. https://doi.org/10.5194/nhess-11-1259-2011.

[2] Islam, M., Imon, T.I. and Polash, A. G., 2019, Analysis of Rainfall Variability in Sylhet Region of Bangladesh: Journal of Water Resource Engineering and Management, v.6(2), pp. 1-10.

[3] Mondal KK (2016) Study of Rainfall and Temperature Trend in Bangladesh. An Unpublished M.Sc. Thesis, Department of Physics, Khulna University of Engineering and Technology, Khulna-9203, Bangladesh.

[4] Saha S, Ahmed SS, Hossain M and Roy MK (2020) Study of Clay Minerals of the Sediments of the Jayanti Estuary, Shariatpur-Barisal, Bangladesh. International Journal of Recent Research and Applied Studies, 7, 4(2): 6-14.

[5] Zhang K, Yao Y, Qian X and Wang J (2019) Various characteristics of precipitation concentration index and its cause analysis in China between 1960 and 2016. International Journal of Climatology, 1-11. https://doi.org/10.1002/joc.6092. 